\title{
Tuck Jump Assessment as an Indicator for Upper Extremity Injury
}

\section{(ㄷ) (i) (으 $\Theta$}

\author{
Authors \\ Jeff W. Barfield, Gretchen D. Oliver
}

\author{
Affiliation \\ School of Kinesiology, Auburn University, Auburn, United \\ States \\ Key words \\ dynamic movement, injury, overhead athlete, \\ tuck jump assessment, upper extremity

$\begin{array}{ll}\text { received } & 06.05 .2018 \\ \text { revised } & 17.06 .2018 \\ \text { accepted } & 21.06 .2018\end{array}$

\section{Bibliography} \\ DOI https://doi.org/10.1055/a-0655-7345 \\ Sports Medicine International Open 2018; 2: E113-E116 \\ (c) Georg Thieme Verlag KG Stuttgart · New York \\ ISSN 2367-1890

\section{Correspondence} \\ Dr. Gretchen D Oliver \\ School of Kinesiology \\ Auburn University \\ 301 Wire Rd \\ 36849 Auburn \\ United States \\ Tel.: + 1/334/8441 497, Fax: + 1/334/8441467 \\ goliver@auburn.edu \\ www.sportsmedicineandmovement.com
}

\begin{abstract}
The purpose of this study was to determine if tuck jumps can be used as a dynamic movement assessment to ascertain a previous history of upper extremity injury in an overhead throwing sport. Seventy-one youth baseball and softball athletes ( 28 baseball/43 softball; $12.41 \pm 2.22$ yrs.; $161.98 \pm 13.65 \mathrm{~cm}$; $59.17 \pm$ $14.90 \mathrm{~kg}$ ) were recruited to participate and were placed in either the previous injury $(N=18)$ or no previous injury $(N=53)$ groups. Kinematic data were collected from jumps 4 through 8 during a trial of 10 tuck jumps performed at $100 \mathrm{~Hz}$ using an electromagnetic tracking system (trakSTAR ${ }^{\mathrm{TM}}$, Ascension Technologies, Inc., Burlington, VT, USA) synced with the MotionMonitor $^{\circledR}$ (Innovative Sports Training, Chicago, IL, USA). A logistic regression showed no significance in trunk flexion or upper leg elevation in the ability to determine upper extremity injury $\left(x^{2}\right.$ $(1, N=71)=3.55, p=0.315)$. In conclusion, examining only trunk flexion and upper leg elevation during the tuck jump assessment (TJA) is not enough for clinicians to recognize previous upper extremity injury. Even though the body behaves as a kinetic chain, simplifying the dynamic movement assessment while not specifying the type of upper extremity injury is not favorable for the clinician to identify previous injury.
\end{abstract}

\section{Introduction}

Diagnosis of a potential counterintuitive variable observed through a dynamic movement assessment, which directly affects an overhead athlete's upper extremity health, should be of interest to coaches and practitioners alike. Because athletes do not tell the whole story on a medical history questionnaire, it would be to the practitioner's advantage to be able to watch a dynamic movement, see a possible contraindication, and ask the right follow-up questions. Overhead athletes are in danger for a multitude of injuries including partial articular-sided supraspinatus tendon avulsion (PASTA) and superior labrum anteroposterior (SLAP) tears because of the humeral head angulation against the glenoid capsule [4].

However, clinical recognition by sports medicine personnel of movement abnormalities, such as a SICK scapula (scapular malposition, inferior medial border prominence, coracoid pain and malposition, and dyskinesis of scapular movement), can help prevent injury among overhead athletes $[1,4,15,19]$.

Although overhead athletes typically sustain injury to the upper extremity, practitioners are aware that the body behaves as a kinetic chain. Because of the dynamic nature of the overhead throw, the lower extremity generates a substantial amount of force during the throwing motion [6]. Additionally, a relationship found between the trunk flexors, hip extensors and scapular dyskinesis [16] shows the interconnectivity of the human body. These latest find- 
ings between the function of the lower extremity and dysfunction of the upper extremity reiterate the importance of the clinical awareness of the pathomechanics within the kinetic chain that can hinder overhead athlete performance and increase their risk of injury [3]. A most recent review of exercise prescription for overhead athletes with shoulder pathologies suggested that rehabilitation address all aspects of injury and recovery including exercises based on local, regional, and global approaches and exercises based on the specific athletic movement [23]. Because rehabilitation programs aim to address local and global stabilizers of the lumbopelvic-hip complex (LPHC), dynamic assessments for overhead athletes should focus on the LPHC.

Because the body behaves as a kinetic chain, any abnormal neuromuscular control could alter the forces in the upper extremity during an overhead movement $[1,3,8]$. However it should be noted that in examining core stability and its impact on upper extremity injury, there is limited support regarding core stability training in injury prevention or performance enhancement [18]. Further examination into the kinetic chain and overhead movements show that low back pain has been reported in $3-15 \%$ of active baseball players and results from abnormal motion and extra stresses placed along the spine in the act of either batting or throwing [21]. In an attempt to prevent and properly rehabilitate a lower back injury, clinicians should assess an athlete's LPHC [20]. Additionally, when examining professional baseball pitchers, it was concluded that poor LPHC control was associated with missing significant time due to injury [2]. Subsequently, it was reported that there is a significant association between low back and knee pain with elbow and shoulder pain among youth baseball players [17]. Because of the relationship between weak LPHC and injury $[2,17]$, clinicians should consider a dynamic assessment that includes kinetic chain efficiency between the lower extremity and LPHC.

When using the tuck jump assessment (TJA) as a dynamic movement assessment, clinicians note movement flaws in order to determine injury potential and provide further training in an attempt to improve movement contraindications. The TJA is known as a dynamic assessment for lower extremity injury [9-12]. Identifying a movement contraindication of knee valgus helps identify the potential for ACL injury [11]. Therefore, in an attempt to determine if the TJA could be used for the upper extremity, it was our purpose to determine if tuck jumps could be used as a dynamic movement assessment to ascertain a previous history of upper extremity injury in an overhead throwing sport. We hypothesized that a more flexed trunk and less elevated upper leg in the peak apex of the tuck jump would correlate with a previous history of upper extremity injury for the overhead athlete.

\section{Materials \& Methods}

\section{Participants}

Seventy-one youth baseball and softball athletes ( 28 baseball/43 softball; $12.41 \pm 2.22$ yrs.; $161.98 \pm 13.65 \mathrm{~cm} ; 59.17 \pm 14.90 \mathrm{~kg}$ ) were recruited to participate. All participants were in good physical condition and had no injuries within the last six months. A health history form was completed by the participants prior to participa- tion. If participants indicated that they had any upper extremity injury in the past year, whether acute or chronic, that had kept them from competition, then they were placed in the previous injury group $(\mathrm{N}=18)$. All other participants were placed into the no previous injury group $(N=53)$. Participants who indicated they had a previous lower extremity injury were excluded from the study. The university's Institutional Review Board approved all testing protocols. Informed written consent was obtained from each participant and the participant's parents before testing [5].

\section{Protocol}

Kinematic data were collected at $100 \mathrm{~Hz}$ using an electromagnetic tracking system (trakSTAR ${ }^{T M}$, Ascension Technologies, Inc., Burlington, VT, USA) synced with the MotionMonitor ${ }^{\circledR}$ (Innovative Sports Training, Chicago, IL, USA). Fourteen electromagnetic sensors were attached at the following locations: (1) posterior aspect of the torso at the first thoracic vertebrae (T1) spinous process; (2) posterior aspect of the pelvis at the first sacral vertebrae (S1); (3-4) flat, broad portion of the acromion on bilateral scapula; (5-6) lateral aspect of the bilateral upper arm at the deltoid tuberosity; (7-8) posterior aspect of the bilateral distal forearm, centered between the radial and ulnar styloid processes; (9) dorsal aspect of the second metatarsal of the non-dominant foot; (10-11) lateral aspect of the bilateral upper leg, centered between the greater trochanter and the lateral condyle of the knee; (12-13) lateral aspect of bilateral lower leg, centered between the head of the fibula and lateral malleolus [7]; and (14) dorsal aspect of the third metacarpal of the dominant hand. A fifteenth, movable sensor was attached to a plastic stylus used for the digitization of bony landmarks $[13,14,24,25]$. The error in determining position and orientation of the electromagnetic sensors with the current calibrated world axis system was less than $0.01 \mathrm{~m}$ and $3^{\circ}$. For the world axis, the positive $y$-axis represented the vertical direction, the positive $x$-axis was anterior to the participant, and the positive $z$-axis was orthogonal to the $x$ and $y$ axis. Position and orientation of the body segments were obtained using Euler angle sequences that were consistent with the International Society of Biomechanics standards and joint conventions [24, 25]. All pelvis and trunk motions were captured in reference to the world axis. All kinematic data from an appendage were captured in reference to the proximal segmental axis. All raw data were independently filtered along each global axis using a $4^{\text {th }}$-order Butterworth filter with a cutoff frequency of $13.4 \mathrm{~Hz}[13,14,22]$. All data were time-stamped through The MotionMonitor ${ }^{\circledR}$ and passively synchronized using a data acquisition board. Following sensor attachment and digitization, each participant performed 10 tuck jumps [11]. Of the 10 tuck jump trials, only trials 4 through 8 were analyzed.

\section{Statistical analysis}

All data were processed by Matlab and analyzed using SPSS version 21 for Windows (SPSS, Chicago, IL, USA). The Shapiro-Wilk test of normality was used with the data to determine normality. After data were determined to be normal, a logistic regression was run to explore if an upper extremity injury could be determined through examining trunk flexion and upper leg elevation during a tuck jump. A priori was set at a level of $p=0.05$ to determine significance. 


\section{Results}

A logistic regression showed no significance in trunk flexion or upper leg elevation in the ability to determine upper extremity injury $\left(x^{2}(1, N=71)=3.55, p=.315\right)$. The model explained $7.2 \%$ of the variance in upper extremity injury and correctly classified $73.2 \%$ of all cases. The logistic regression coefficient, Wald test, and odds ratio for each of the predictor variables can be found in > Table 1. Descriptive statistics can be found in > Table 2 .

\section{Discussion}

The purpose of this study was to determine if a previous upper extremity injury in an overhead throwing athlete alters tuck jump movement patterns. We hypothesized that a TJA could determine previous upper extremity injury, however this hypothesis was not supported. The TJA was created by clinicians to identify high-risk landing mechanics and provide direction regarding lower extremity injury [11]. However, upon examination of upper extremity injury, simplifying the TJA variables to those that fall into the proximal body control category does not help identify previous a upper extremity injury for the overhead athlete.

Even though the utilization of the tuck jump as a dynamic movement assessment did not reveal any upper extremity injury relationships, the kinetic chain theory holds true $[1,3,8]$. To be classified as injured in this study, participants only needed to indicate that they missed practice and/or game time due to an upper extremity injury. We did not specify the degree of injury or whether it was the onset was acute or chronic for those in our injured group. Because a link between baseball players exhibiting throwing shoulder and elbow pain with knee and low back pain exists, clinicians should consider examining the trunk and lower extremities in those throwing athletes with an upper extremity injury [17]. However, based on the current findings, further examination into the TJA is warranted.

Although a direct link was not found between the TJA and upper extremity injury, further investigation into injury precursors should be performed. During our TJA, we examined only trunk flexion and upper leg elevation, which are two variables that make up the proximal control factor indicated by Lininger and colleagues [9]. In their

- Table 1 Logistic regression predicting upper extremity injury from trunk flexion, right upper leg elevation, and left upper leg elevation.

\begin{tabular}{|l|c|c|c|c|}
\hline Predictor & $\boldsymbol{\beta}$ & Wald $\mathbf{X}^{\mathbf{2}}$ & $\mathbf{P}$ & $\begin{array}{c}\text { Odds } \\
\text { Ratio }\end{array}$ \\
\hline Trunk Flexion & -0.02 & 0.806 & 0.369 & 0.98 \\
\hline Right UL Elevation & -0.01 & 0.059 & 0.808 & 0.99 \\
\hline Left UL Elevation & 0.03 & 0.736 & 0.391 & 1.03 \\
\hline
\end{tabular}

> Table 2 Descriptive statistics for trunk flexion, right upper leg elevation, and left upper leg elevation.

\begin{tabular}{|l|c|r|}
\hline Predictor & Injured & \multicolumn{1}{c|}{ Healthy } \\
\hline Trunk Flexion, $^{\circ}$ & $-24.14(12.87)$ & $-18.89(12.71)$ \\
\hline Right UL Elevation, $^{\circ}$ & $73.41(14.49)$ & $67.47(16.85)$ \\
\hline Left UL Elevation, $^{\circ}$ & $76.27(13.52)$ & $68.41(19.04)$ \\
\hline \multicolumn{2}{|l|}{ Note: Data are presented in table as Mean (SD). } \\
\hline
\end{tabular}

exploratory factor analysis, it was concluded that three factors, defined as fatigue, distal landing pattern, and proximal control, should be examined to get the most benefit of the TJA in injury assessments [9]. We simplified their conclusion to look at the one factor that would have the strongest relationship with the upper extremity. Our results agree with their conclusion that a simplified unidimensional construct of the TJA may not be the best way to use this dynamic movement assessment to identify previous upper extremity injury.

Future research should consider examining the relationship between fatigue as determined in the TJA with upper extremity injury. Also, future research should examine the relationship of the TJA with chronic upper extremity injuries. Limitations to this study include using a survey to identify the injured group. Perhaps a test of scapular dyskinesis to separate groups would have been more reliable and shown more of a relationship with TJA variables. Other limitations include a limited injured group sample size and time away from injury. All participants who reported for this study were presumed to be injury-free for the past 6 months. The time away from injury may be enough to correct kinetic chain deficiencies.

In conclusion, the TJA is a complex dynamic movement assessment in which even the unidimensional analysis construct has 10 points of potential deficits for the clinician to assess. Although the TJA is a known assessment for lower extremity injury [10-12], research says little regarding upper extremity injury. Examining only trunk flexion and upper leg elevation during the TJA is not enough for clinicians to recognize a previous upper extremity injury. Even though the body behaves as a kinetic chain, simplifying the dynamic movement assessment while not specifying the type of upper extremity injury is not favorable for the clinician to identify previous injury.

\section{Conflicts of Interest}

The authors declare that they have no conflict of interest.

\section{References}

[1] Burkhart SS, Morgan CD, Kibler WB. The disabled throwing shoudler: Spectrum of pathology. Part III: The SICK scapula, scapular dyskinesis, the kinetic chain, and rehabilitation. Arthroscopy 2003; 19: 641-661

[2] Chaudhari AM, McKenzie CS, Pan X, Onate JA. Lumbopelvis control and days missed because of injury in professional baseball pitchers. Am J Sports Med 2014; 42: 2734-2740

[3] Chu SK, Jayabalan P, Kibler WB, Press J. The kinetic chain revisited: New Concepts on throwing mechanics and injury. PM R 2016; 8: S69-S77

[4] Edmonds EW, Dengerink DD. Common conditions in the overhead athlete. Am Fam Physician 2014; 89: 537-541

[5] Harriss D, MacSween A, Atkinson G. Standards for ethics in sport and exercise science resaerch: 2018 update. Int J Sports Med 2017; 38: 1126-1131

[6] Kageyama M, Sugiyama T, Takai Y, Kanehisa H, Maeda A. Kinematic and kinetic profiles of trunk and lower limbs during baseball pitching in collegiate pitchers. J Sports Sci Med 2014; 13: 742-750 
[7] Keeley DW, Oliver GD, Dougherty CP. Shoulder kinematics during pitching: Comparing the slide step and traditional stretch deliveries. Hum Mov Sci 2012; 31: 1191-1199

[8] Kibler WB, Press ], Sciascia A. The role of core stability in athletic function. Sports Med 2006; 36: 189-198

[9] Lininger MR, Smith CA, Chimera N, Hoog P, Warren M. Tuck jump assessment: An exploratory factor analysis in a college age popularion. J Strength Cond Res 2017; 31: 653-659

[10] Myer GD, Brent JL, Ford KR, Hewett TE. Real-time assessment and neuromuscular training feedback techniques to prevent $\mathrm{ACL}$ injury in female athletes. Strength Cond J 2011; 33: 21-35

[11] Myer GD, Ford KR, Hewett TE. Tuck jump assessment for reducing anterior cruciate ligament injury risk. Athl Ther Today 2008; 13: $39-44$

[12] Myer GD, Ford KR, Khoury J, Succop P, Hewett TE. Development and validation of a clinic-based prediction tool to identify female athletes at high risk for anterior cruciate ligament injury. Am J Sports Med 2010; 38: 2025-2033

[13] Oliver GD, Keeley DW. Gluteal muscle group activation and its relationship with pelvis and torso kinematics in high-school baseball pitchers. J Strength Cond Res 2010; 24: 3015-3022

[14] Oliver GD, Keeley DW. Pelvis and torso kinematics and their relationship to shoulder kinematics in high-school baseball pitchers. J Strength Cond Res 2010; 24: 3241-3246

[15] Page P. Shoulder muscle imbalance and subacromial impingement syndrome in overhead athletes. Int J Sports Phys Ther 2011; 6: 51-58

[16] Pires ED, Camargo PD. Analysis of the kinetic chain in asymptomatic individuals with and without scapular dyskinesis. Clin Biomech 2018; 54: 8-15

[17] Sekiguchi T, Y. H Momma H, Tsuchiya M, Kuroki K, Kanazawa K, Yabe Y, Yoshida S, Koide M, Itaya N, Itoi E, Nagatomi R. Coesistence of trunk or lower extremity pain with elbow and/or shoudler pain among young overhead athlets: A cross-sectional study. Tohoku J Exp Med 2017; 243: $173-178$
[18] Silfies SP, Ebaugh DD, Pontillo M, Butowicz C. Critical review of the impact of core stability on upper extremity athletic injury and performance. Braz J Phys Ther 2015; 19: 360-368

[19] Thomas S], Swanik KA, Swanik C, Huxel KC, Kelly JDt. Change in glenohumeral rotation and scapular position after competitive high school baseball. J Sport Rehabil 2010; 19: 125-135

[20] Wasser JG, Zaremski JL, Herman DC, Vincent HK. Assessment and rehabilitation of chronic low back pain in baseball: Part II. Res Sports Med 2017; 25: 231-243

[21] Wasser JG, Zaremski JL, Herman DC, Vincent HK. Prevalence and proposed mechanisms of chronic low back pain in baseball: Part I. Res Sports Med 2017; 25: 219-230

[22] Wicke J, Keeley DW, Oliver GD. Comparison of pitching kinematics between youth and adult baseball pitchers: A meta-analytic approach. Sports Biomech 2013; 12: 315-323

[23] Wright AA, Hegedus E], Tarara DT, Ray SC, Dischiavi SL. Exercise prescription for overhead athletes with shoulder pathology: A systematic review with best evidence synthesis. Br J Sports Med 2017, doi:10.1136/bjsports-2016-096915

[24] Wu G, Siegler S, Allard P, Kirtley C, Leardini A, Rosenbaum D, Whittle M, D'Lima DD, Cristofolini L, Witte H, Schmid O, Stokes I. ISB recommendation on definitions of joint coordinate system of various joints for reporting of human joint motion-Part I: Ankle, hip, and spine. J Biomech 2002; 35: 543-548

[25] Wu G, van der Helm FCT, Veeger HE], Makhsous M, Van Roy P, Anglin C, Nagels J, Karduna AR, McQuade K, Wang X, Werner FW, Buchholz B. ISB recommendation on definitions of joint coordinate systems of various joints for the reporting of human joint motion-Part II: Shoulder, elbow, wrist and hand. J Biomech 2005; 38: 981-992 